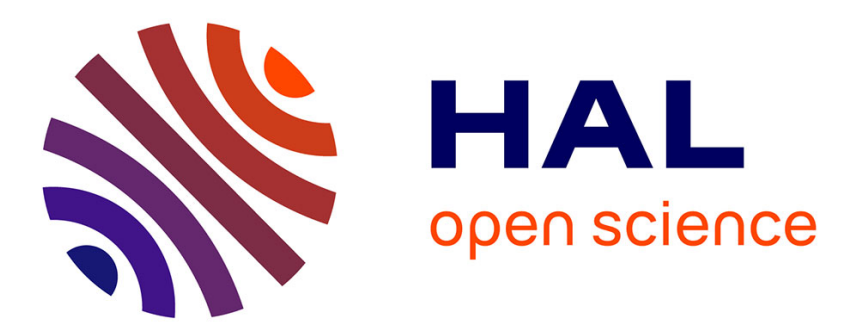

\title{
Impact of maternal prenatal psychological stress on birth weight
}

Joanie Mélançon, Nathalie Bernard, Jean-Claude Forest, Réjean Tessier, Tarabulsy Georges M, Damien Bouvier, Yves Giguère

\section{To cite this version:}

Joanie Mélançon, Nathalie Bernard, Jean-Claude Forest, Réjean Tessier, Tarabulsy Georges M, et al.. Impact of maternal prenatal psychological stress on birth weight. Health Psychology, 2020, 39 (12), pp.1100-1108. 10.1037/hea0001017 . hal-03248078

\section{HAL Id: hal-03248078 \\ https://hal.uca.fr/hal-03248078}

Submitted on 3 Jun 2021

HAL is a multi-disciplinary open access archive for the deposit and dissemination of scientific research documents, whether they are published or not. The documents may come from teaching and research institutions in France or abroad, or from public or private research centers.
L'archive ouverte pluridisciplinaire HAL, est destinée au dépôt et à la diffusion de documents scientifiques de niveau recherche, publiés ou non, émanant des établissements d'enseignement et de recherche français ou étrangers, des laboratoires publics ou privés. 
Joanie Mélançon and Nathalie Bernard, Research Center CHU de Québec-Université Laval, Canada; Jean-Claude Forest, Research Center CHU de Québec-Université Laval and Department of Molecular Biology, Medical Biochemistry and Pathology, Laval University, Canada; Réjean Tessier, School of psychology, Laval University, Canada; Georges M. Tarabulsy, School of psychology and Laval University Centre for Research on Youth and Families, Laval University, Canada; Damien Bouvier, Department of Biochemistry and Molecular Genetics, CHU Clermont-Ferrand and UCA, CNRS, INSERM, GReD, ClermontFerrand, France; Yves Giguère, Research Center Québec-Université Laval and Department of Molecular Biology, Medical Biochemistry and Pathology, Laval University, Canada.

This research was supported by Canadian Institutes of Health Research (CIHR, Healthy Pregnancy Initiative from the Institute for Human Development, Child and Youth Health).

Correspondence concerning this article should be addressed to Dr. Yves Giguère, Centre de recherche du CHU de Québec-Université Laval, 10 rue de L’Espinay, Québec city, Québec, G1L 3L5, Canada . Email : yves.giguere@crchudequebec.ulaval.ca 


\section{Abstract}

Objective: The study aimed to evaluate the impact of prenatal maternal stress on birth weight using a large cohort of predominantly Caucasian women living in an urban area. Method: Women were recruited between 2005 and 2010. Data collection took place between the 24th and the 28th week of gestation. The Measure of Psychological Stress (MSP-9), a validated tool to assess stress symptoms, was used to collect data on prenatal maternal stress (independent variable). Birth weight (dependent variable) was classified as low birth weight (LBW; $<2,500 \mathrm{~g}$ ), normal birth weight (NBW; 2,500-4,000 g), and macrosomia $(>4,000 \mathrm{~g})$. Adjusted odd ratios (aOR) were obtained after performing multivariate logistic regressions adjusted for potential cofounders. At the final stage, 5,721 women were included in analysis. Results: When compared with women experiencing low stress, participants with high-stress scores were at increased risk of delivering an infant with LBW before adjustment $[\mathrm{OR}=2.06$, 95\% CI (1.04-4.09)], but, after adjustment, only a nonsignificant trend remained. However, women experiencing intermediate and high levels of stress were at increased risk of delivering a baby with macrosomia, even after adjustment $[\mathrm{aOR}=1.23 ; 95 \% \mathrm{CI}(1.02-1.49)]$ and $[\mathrm{aOR}=1.76 ; 95 \% \mathrm{CI}(1.11-2.77)]$ compared to those who scored low on the psychological stress scale. Conclusion: Women exposed to high self-reported psychological stress during second trimester $\left(24^{\text {th }}\right.$ to $28^{\text {th }}$ weeks $)$ of pregnancy have a 1.7 -fold increased risk for delivering a baby with macrosomia when compared to women exposed to low psychological stress.

Keywords: prenatal psychological stress, pregnancy, fetal macrosomia, low birth weight infant 


\section{Impact of Maternal Psychological Stress on Birth weight}

Birth weight is an important predictor of the newborn short and long-term health. Low birth weight (LBW) and macrosomia increase the risk of morbidity and mortality (Ay et al., 2009; Boulet, Alexander, Salihu, \& Pass, 2003; Canadian Institute for Health Information, 2009) Newborns weighing under 2,500 grams, defined as low birth weight (LBW) by the World Health Organization (WHO) (United Nations Children's Fund and World Health Organization, 2004) have a higher risk, especially if they have very LBW $(<1,500 \mathrm{~g})$, to suffer from cerebral palsy, deafness, blindness, epilepsy, chronic lung disease, learning disabilities, and attention deficit disorders (Bergman et al., 1985; Dunn, Robertson, \& Crichton, 1986; Ellenberg \& Nelson, 1979; Gallo \& Lennerstrand, 1991; Kraybill, Bose, \& D'ercole, 1987; McCormick, Gortmaker, \& Sobol, 1990). On the other hand, while there is no consensus regarding the definition of macrosomia (Boulet et al., 2003; Ye et al., 2015), newborns weighing more than 4,000 g are generally defined as having macrosomia since this threshold could indicate higher risk of adverse obstetric and neonatal outcomes (Dubois, Girard, \& Tatone-Tokuda, 2007; Wang et al., 2016). Macrosomia increases the risk of shoulder dystocia (Benedetti \& Gabbe, 1978), clavicular fracture, and brachial palsy (Boyd, Usher, \& Mclean, 1983), prolongation of the second and third stage of labor, instrumented vaginal delivery, emergency caesarean section, Apgar score lower than four, neonatal hypoglycemia, and admission at the neonatal intensive care unit (Jolly, Sebire, Harris, Regan, \& Robinson, 2003; Mohammadbeigi et al., 2013), to name only a few. Adverse outcomes related to both extremes of the birth weight spectrum thus represent an obstetrical challenge.

In Canada over the last fourteen years, the rate of LBW increased, from 5.6\% in 2000 to $6.4 \%$ in 2015 (Statistics Canada, 2016). Neonates weighing >4,500 g and large for gestational age (LGA) represented $1.5 \%$ and $9.5 \%$ of all Canadian births in 2015 (Statistics Canada, 2016). Several factors are known to contribute to LBW and macrosomia. LBW is 
more common in women with unfavorable socioeconomic level, chronic hypertension or nephropathy, tobacco, alcohol or drug consumption (de Bernabé et al., 2004), whereas risk factors for macrosomia include mothers with a prepregnancy body mass index (BMI) >30, parity $>4$, age $>40$, and preexisting diabetes or gestational diabetes mellitus (GDM) (Jolly et al., 2003).

In the past years, psychological stress has been proposed to play a role in birth weight, especially LBW (E. L. Bussieres et al., 2015). Various hypotheses have been proposed, but research has yielded few stable findings. Some studies observed a link between maternal stress and LBW (Dolatian et al., 2016; Hashim \& Moawed, 2000; Rondó et al., 2003), while others did not (Sable \& Wilkinson, 2000; Wing et al., 2017). Hashim and Moawed found that an intermediate score on a life stressor scale doubled the risk of giving birth to a baby with LBW $[\mathrm{OR}=2.0,95 \%$ CI (1.2-3.2)] in a cohort of 500 Saudi women (Hashim \& Moawed, 2000). Similarly, a study conducted by Rondó et al. involving 865 Brazilian participants showed that, when compared to women experiencing low levels of stress, high-stress mothers were twice as likely to deliver a baby with $\mathrm{LBW}[\mathrm{OR}=1.97,95 \%$ CI 1.12-3.47)] (Rondó et al., 2003). Liou et al. found that stress measured after 24 weeks of gestation could not predict the occurrence of LBW (Liou, Wang, \& Cheng, 2016). Wadhwa et al. had previously found that perceived stress was not related with birth weight in a group of mostly married, employed, Caucasian women with annual family income $>\$ 50,000$ (Wadhwa, Sandman, Porto, Dunkel-Schetter, \& Garite, 1993). Bussières et al. showed that the relation between maternal prenatal stress and LBW was modest but significant, and that this link was related to different and significant moderators such as type of stress and type of population (high or low risk) (E. L. Bussieres et al., 2015).

In contrast, the link between prenatal maternal psychological stress and macrosomia is not well studied. The quality of life is impaired by decreased self-confidence, anxiety, stress 
and depression. Jakubauskiene et al. found that lower score of quality of life (evaluated by mental and physical health scores) during the first trimester are associated with LGA newborns (Jakubauskiene et al., 2019). Tegethoff et al. observed that life stress, defined as perceptions of important difficulties in major areas such as finances, relationships, work, pregnancy, housing, and health, was associated with increased birth weight after controlling for duration of gestation. (Tegethoff, Greene, Olsen, Meyer, \& Meinlschmidt, 2010a). A Canadian study founded that the relationship between social disparities and macrosomia varied by geographic region (Dubois et al., 2007).

A frequently cited mechanism to explain the relation between prenatal stress and birth weight involves the hypothalamic-pituitary-adrenal (HPA) axis (Beijers, Buitelaar, \& de Weerth, 2014; Gilles et al., 2018). Stress can induce dysfunction of the HPA axis. Prenatal maternal psychological distress may alter molecular mechanisms that regulate fetal exposure to maternal cortisol (Togher, O'Keeffe, Khashan, Clarke, \& Kenny, 2018). Overexposure to maternal cortisol has been associated with reduced birth weight (Field et al., 2006).

The placenta is an important mediator for intrauterine fetal development and growth (Nelissen, van Montfoort, Dumoulin, \& Evers, 2011). Tegethoff et al. have observed that maternal life stress during the pregnancy was associated with an increased placenta weight (Tegethoff, Greene, Olsen, Meyer, \& Meinlschmidt, 2010b). Some evidence suggests that maternal cortisol can stimulate the placental release of the corticotropin-releasing hormone $(\mathrm{CRH})$ in fetal and maternal circulation, which is associated with decreased fetal growth and preterm delivery, the two major factors that cause LBW (Hobel \& Culhane, 2003; Rakers et al., 2017). It is also known that norepinephrine can indirectly affect the fetus by reducing uteroplacental perfusion (Rakers et al., 2017). Reduced placental perfusion may lead to fetal undernutrition, reducing fetal growth (Baschat \& Hecher, 2004). Finally, stress may be 
linked to other behaviors that may affect birthweight, such as smoking, alcohol and drug use, poor nutrition, and loss of sleep (Gennaro \& Hennessy, 2003).

Also, imprinted genes have been demonstrated to play important roles prenatally regulating fetal growth, placental development and signaling between the mother and her fetus (John, 2017). It has been hypothesized that aberrant imprinting in the placenta contributes to the co-occurrence of complications of pregnancy including LBW and maternal mood disorders (John, 2017). A recent genome-wide association study highlighted maternal genetic effects on the birth weight that are independent of fetal genetics (Beaumont et al., 2018). They have identified variants in the maternal genome that are robustly associated with newborn birth weight (Beaumont et al., 2018). This study aimed to evaluate the impact of prenatal maternal psychological stress on birthweight using a large cohort of predominantly Caucasian women living in an urban area. We hypothesized that high maternal psychological stress results in an unfavorable impact on birth weight. Many studies that have investigated the prenatal effects of stress on birth weight have been done in low socioeconomic status populations. The relevance of this study lies in the fact that it was performed from a largescale prospective cohort of pregnant women $(n=5,721)$ and in a socioeconomic context that is mostly favorable.

\section{Method}

\section{Study Design}

This study is based on a large prospective cohort on pregnancies complications that includes 7,866 pregnant women recruited at the Centre Hospitalier Universitaire (CHU) de Quebec-Université Laval from April 2005 to March 2010 (A comprehensive Healthy Pregnancy Initiative from the Institute for Human Development, Child and Youth Health, Canadian Institutes of Health Research). Details of the original study design can be found 
elsewhere (Bernard et al., 2019; Giguere et al., 2015; Theriault, Giguere, Masse, Girouard, \& Forest, 2016; Woolcott et al., 2016). Pregnant women aged to 18 years or older and without chronic hepatic or renal diseases were invited to participate in the biobank. Women whose pregnancies included major fetal anomalies or that were terminated prior to 20 weeks of gestation because of miscarriage, voluntary pregnancy termination or fetal death were excluded of the present study (figure 1). Furthermore, women lost to follow-up or with missing delivery data, as well as women with a multiple pregnancy, were excluded. This left a sample of 7492 women with singleton pregnancy of more than 20 weeks. From this sample, 1771 women were excluded either because of missing data, the psychological stress questionnaire was not completed or the child was born with major congenital anomaly or was stillborn. The final sample included 5,721 women (figure 1). Participants gave written informed consent and the study was approved by the CHU de Quebec-Universite Laval Ethics Review Board (initial approval date: 9 November 2004, Project 5-04-10-01 [95.05.17], SC12-01-159).

Infant birth weight was classified within three categories: LBW $(<2,500 \mathrm{~g})$, normal birth weight (NBW; 2,500-4,000 g), and macrosomia (>4,000 g).

\section{Data Collection}

Data collection took place during the $50 \mathrm{~g}$ glucose challenge test performed between the $24^{\text {th }}$ and the $28^{\text {th }}$ week of gestation. Women were invited to complete a questionnaire that included information about their past medical and family history, life habits (tobacco, alcohol, drugs, physical activity, nutrition, etc.), sociodemographic characteristics (ethnicity, marital status, annual household income, highest level of education, employment status, etc.), anthropometric measures (age, height, weight), and perceived level of stress.

Infant anthropometric measures and obstetrical and neonatal complications were collected by research nurses from participant medical records following delivery. Medical 
history, including gynecological and obstetrical history during the pregnancy, was also collected from the medical records.

\section{Measure of Psychological Stress (MSP)}

The MSP-9 questionnaire was used to collect data on prenatal maternal stress (Langevin, François, Boini, \& Riou, 2012). The MSP-9 is a validated questionnaire used to assess stress symptoms felt by someone in the last four to five days. Developed by Lemyre and Tessier, this unidimensional scale is divided in three distinctive domains: cognitiveaffective, somatic, and behavioral (Lemyre \& Tessier, 2003). The original version contains 45 items. A shorter nine-items version (MSP-9) was created in 2002 to meet research needs. This version meets the same reliability and validity criteria as the original measure and has an , internal consistency of .89 (Lemyre \& Tessier, 2003). A four point likert scale is used to answer each of the nine stress items: (1) "Never", (2) "Sometimes", (3) "Often", (4) "Very Often". A result from 9 to 15 was classified as low stress (perceived stress $\leq$ the general population average), between 16 and 25 as intermediate stress (perceived stress above the general population average), and above 26 as high stress (extreme perceived stress) (Lemyre \& Tessier, 2003).

\section{Statistical Analyses}

Continuous variables were expressed as mean \pm one standard deviation (SD). Characteristics of mothers who gave birth to an infant with LBW or macrosomia and those who did not (i.e. NBW newborns) were compared using z-test for categorical variables and Mann-Whitney U-test for continuous variables. Odds ratios and their 95\% confidence intervals were obtained after performing multinominal logistic regressions with infant birth weight (LBW, NBW, Macrosomia) as the dependent variable and the level of stress following the classification obtained from the MSP-9 questionnaire as the independent variable. As a first step, to determine which confounders will be added to the multivariate model, we 
performed univariate logistic regression for each potential variable. A $p$-value of $<.2$ in univariate analysis was set for entry of the variable in multivariate analysis. The following potential confounders were tested in univariate analysis: gestational age at delivery, parity (nulliparous, multiparous), maternal age, prepregnancy BMI, weight gain during pregnancy, ethnicity (2 Caucasian parents, Not 2 Caucasians parents, Unknown), level of education (University, Collegial, High school, None, Unknown), annual household income (>60,000\$, between 40,000-59,999\$, <40,000\$, Unknown), marital status (Married/commun law, Others, Unknown), alcohol intake (0/week, $\leq 1 /$ week, $>1$ /week, Unknown), drug consumption during pregnancy (No, Yes, Unknown), smoking status (Smoker, Ex-smoker, Nonsmoker, Unkown), antidepressants or anxiolytics use during pregnancy (No, Yes, Unknown), gender of the baby, hypertension (No, Preeclampsia, Gestational hypertension), and glucose disorders during pregnancy (No, GDM, IGT), past history of preterm delivery (Yes, No), past history of pregnancy termination (Yes, No) or miscarriage (Yes, No). As second step, the selected variables were added at the multivariate logistic regression. If the variable did not contribute significantly to the model, it was remove. In the final model, the odds ratios were adjusted for maternal age, gestational age at delivery, parity, prepregnancy BMI, weight gain during pregnancy, presence of hypertension during pregnancy, smoking status and gender of the baby. Results were considered significant if the $p$ value was $<.05$. Data were analysed using XLSTAT 2018.6 software.

\section{Results}

\section{Characteristics of the study population}

Of the 5,721 pregnant women included in the final analysis, 175 babies weighed less than 2,500 grams $(3.1 \%)$ and 611 weighed more than 4,000 grams (10.7\%). Participant anthropometric and sociodemographic characteristics are described in Table 1. Table 2 refers to obstetrical characteristics for the three groups of mothers. Infants with LBW, when 
compared to newborns with NBW, were more prone to be born from a mother who smoked, suffered from preeclampsia, delivered by caesarean section, experienced a previous preterm birth, and had a previous psychiatric diagnosis. Newborns with LBW were also more likely to be female. Newborns over 4,000 g, when compared to babies with normal birth weight, were more likely to be males, to be born from an older mother with a higher BMI, and delivered by caesarean section, but less likely to be born from nulliparous, smoking mothers who drank alcohol more than once per week, although the percentage of subjects in this latter group was low (1.1\% in NBW vs $0.34 \%$ in the macrosomia subgroups).

\section{Association between psychological stress and birth weight}

\section{Low birth weight}

Women who obtained an intermediate score on the MSP-9 did not present a higher risk of giving birth to an infant with LBW, both before and after adjustment for confounders $[\mathrm{aOR}=1.37,95 \% \mathrm{CI}(0.88-2.12)]$ (Table 3$)$. Those who scored high were at increased risk to deliver a LBW baby before adjustment $[\mathrm{OR}=2.06,95 \% \mathrm{CI}(1.04-4.09)]$, but the association did not remain significant after adjustment $[\mathrm{aOR}=2.09,95 \%$ CI $(0.83-5.26)]$ (Table 3$)$. However, it was observed that as the level of stress of the participants increased, the odds ratios, even if not statistically significant, increased.

\section{Macrosomia}

Expecting mothers who scored intermediate or high on the MSP-9 were at greater risk of giving birth to a newborn with macrosomia, both before and after corrections for confounders. After adjustment, risk almost doubled for women experiencing high levels of stress in comparison to those experiencing low levels of stress $[\mathrm{aOR}=1.76 ; 95 \% \mathrm{CI}(1.11$ 2.77)]. Risk for macrosomia was $23 \%$ greater in women at intermediate-stress levels [aOR = $1.23 ; 95 \%$ CI (1.02-1.49)] (Table 3). 


\section{Discussion}

Our study aimed to evaluate the impact of prenatal maternal psychological stress during the second trimester on birth weight in a population of mostly Caucasian women from relatively favorable socioeconomic contexts. Results indicate that maternal prenatal stress is not significantly related to LBW after confounding variables were accounted for, even though a two-fold increase in the rates of LBW infants was noted for women who scored high on the MSP-9 stress measure. The most intuitive explanation for the absence of a statistically significant association is the insufficient analytical power. Only 175 out of more than 5,000 women gave birth to an infant with LBW (3.1\%), which is lower than what would be expected (6.4\% in 2015)(Statistics Canada, 2016). Some studies did not find a statistically significant relationship between prenatal psychological stress and LBW (Wadhwa et al., 1993; Wang et al., 2016), unlike other studies (A. E. Borders, W. A. Grobman, L. B. Amsden, \& J. L. Holl, 2007; Hashim \& Moawed, 2000; Rondó et al., 2003; Stylianou-Riga et al., 2018). There are explanations for apparent inconsistent results relative to the relationship between maternal prenatal stress and infant birth weight. In their meta-analysis, Bussières et al. observed that overall there is a significant but low-level inverse relation between maternal prenatal stress and infant birth weight and gestational age. Also, they observed that the effect on birth weight increased if maternal prenatal stress was pregnancy-specific and if studies were conducted outside of North America and Europe (E. L. Bussieres et al., 2015).

A number of studies that found an association between maternal stress and LBW were conducted in low-income populations (A. E. B. Borders, W. A. Grobman, L. B. Amsden, \& J. L. Holl, 2007; Hashim \& Moawed, 2000; Nkansah-Amankra, Luchok, Hussey, Watkins, \& Liu, 2010), which was not the case with the current sample, where $63 \%$ of women had experienced college-level education or had a university degree, and $51 \%$ had a family income over 60,000 \$(CDN). Of note, our results were consistent with Wadhwa et al. who founded 
that perceived stress was not related with birth weight in a favorable socioeconomic population (Caucasian women mostly married, employed, and with annual family income > $\$ 50,000$ ) (Wadhwa et al., 1993). In the various previous studies, the classification was essentially based on birthweight of less than 2,500 g compared to those weighing more than 2,500 g, leading to a dichotomous approach (LBW vs the rest) (A. E. Borders et al., 2007; Hashim \& Moawed, 2000; Nkansah-Amankra et al., 2010). This classification of birth weight into only two groups that includes macrosomic newborns, as opposed to the classification we used, could possibly influence the association of prenatal stress with the LBW.

Interestingly, our findings show that intermediate and high levels of maternal prenatal stress is significantly associated with the delivery of infants weighing more than $4,000 \mathrm{~g}$. Women exposed to high prenatal stress had a 1.8 -fold increased risk of giving birth to a newborn with macrosomia. To our knowledge, no previous studies conducted on prenatal stress and birth weight had distinguished between infants with normal birth weight and with macrosomia. When using birth weight as a continuous variable, only one other study reported a link between a higher level of perceived life stress and increased birth weight (Tegethoff et al., 2010a). Similar to our study, their Danish population sample was mainly of favorable SES. They suggested that the placenta is a key candidate linking maternal life stress and increased fetal growth. The placenta has two main functions; it provides the fetus with the nutrients and the oxygen it requires for tissue accretion and energy metabolism. It also produces hormones and reacts to maternal hormones and neutrophins that are known to affect fetal growth and development (Fowden, Forhead, Coan, \& Burton, 2008). A neutrophin, brain-derived neurotrophic factor (BDNF), is suggested to play an important role in placental and fetal growth and development. A possible hypothesis explaining the relationship between maternal stress and birth weight is that altered intrauterine concentrations of BDNF may lead 
to abnormal fetal growth. In nondiabetic macrosomic neonates, cord blood BDNF was significantly lower than in neonates with normal birth weight (Cai et al., 2017). Moreover, some studies reported that cord blood BDNF levels were lower in infants born to mothers with major depression and generalized anxiety disorder during pregnancy (Sonmez et al., 2019; Uguz et al., 2013).

Although the biological processes remain unclear, they hypothesized, based on animal studies, that perceived prenatal stress in early pregnancy could lower the concentration of the interleukin 10 (IL10). In mice, lower levels of stress were associated with lower IL10 and increased placental size by $28 \%$ in one study (Roberts, White, Wiemer, Ramsay, \& Robertson, 2003). They also suggested that the pregnancy-associated plasma protein-A (PAPPA), which can be activated by stress-activated signaling pathways (Resch, Oxvig, Bale, \& Conover, 2006), may stimulate the insulin-like growth system, potentially leading to an increase in placental weight.

Research on growth factors linked to stress experience in mice increasingly suggests that stress may affect both placental volume and birth weight through different epigenetic and other mechanisms. Maternal genetic factors may influence fetal growth indirectly through the intra-uterine environment or directly through inheritance by the fetus (Beaumont et al., 2018). The identified loci highlighted potentially relevant maternal traits including fasting glucose, blood glucose, blood pressure, sex hormone levels and immune function (Beaumont et al., 2018). Adaptation to stress is influenced by different factors, such as ...

It is also possible that the heterogeneity of results in the literature may be linked to the diversity of methods used across studies and, in particular, to the definition and measurement of stress. In their meta-analysis, Bussières et al. revealed that studies concerned with pregnancy-related stress yield greater effect sizes than studies that used other definitions of 
stress (E. L. Bussieres et al., 2015). It is therefore difficult to identify the kinds of stress that may affect neonatal outcomes such as LBW or macrosomia. The prenatal stress literature has conceptualized stress as negative life events, psychological distress, physical and psychological strain, perceived stress or daily hassles. The measure of psychological stress used in our study was not used in other studies, which could explain that we found an association between higher maternal prenatal stress and macrosomia.

Several researchers have also suggested that the timing of the stress assessment also needs to be considered. Roy-Matton et al. observed that women with pregnancy complications had significantly higher perceived stress at 10 to 20 weeks of gestation compared to 25 to 30 weeks of gestation, whereas the difference between women with and without pregnancy complications was not significant (Roy-Matton, Moutquin, Brown, Carrier, \& Bell, 2011). Several carefully conducted studies have shown that stress experienced in the first or second trimesters may have more impact on infant birth weight than stress experienced later during pregnancy (Khashan et al., 2014; Lobel et al., 2008). Finally, other researchers have shown that study design also may affect results. Some studies measure stress retrospectively, or examine stress as it might have been experienced by mothers over a long period of time (e.g., one year), whereas other studies examine the prenatal stress-birth weight association prospectively. Such design-based variations may induce differences in results (E.-L. Bussieres et al., 2015; Gennaro \& Hennessy, 2003; Tarabulsy et al., 2014).

\section{Strengths and Limitations}

Our study has numerous strengths. First, this is a large-scale study involving 5,721 participants and which included 175 infants with LBW and 611 neonates with macrosomia. Our design permitted the categorization of birth weight in three groups for analysis, LBW, NBW and macrosomia, which compares favorably to most other studies that relied on a dichotomous approach with respect to birth weight ( $\mathrm{LBW}$ vs infants $>2,500 \mathrm{~g}$ ). Additionally, 
stress was measured directly, i.e. women self-reported their perceived stress level rather than using a diagnosis of depression or anxiety. According to Gennaro and Hennessy (2003), asking women directly about perceived psychological stress, rather than anxiety or depression, could be a more accurate approach to identify acute stress (Gennaro \& Hennessy, 2003). Finally, the prospective design of the study excluded the possibility of recall bias in the measure of maternal stress experience.

There were, however, several limits to the current study. Stress perception was measured only once during pregnancy, between the $24^{\text {th }}$ and $28^{\text {th }}$ week of gestation. Since it is not clear when stress impacts obstetrical outcomes, it could have been useful to obtain repeated measures of stress across trimesters to examine relative contributions to predicting birth weight. Likewise, it would have been useful to operationalize stress in different ways, also to see how different angles on prenatal stress may contribute to predicting infant birth weight.

\section{Conclusion}

In conclusion, in this specific, relatively educated socioeconomically middle-class population of Caucasian women, maternal prenatal psychological stress measured between the $24^{\text {th }}$ and the $28^{\text {th }}$ week of gestation was associated with a higher risk of delivering a baby with macrosomia. This association requires corroboration by future research. There was also a two-fold, nonsignificant trend of delivering a newborn with LBW with increased maternal stress, after controlling for confounding variables. Considering the consequences of both macrosomia and LBW on the newborn's immediate and future health, healthcare prevention programs that help lower stress during pregnant women would probably be beneficial to improving infant birth weight. 


\section{Acknowledgements}

The authors thank all study participants. We also thank the research nurses for the recruitment of participants and retrieval of data from the medical records. This work was supported by the Canadian Institutes of Health Research (CIHR, Healthy Pregnancy Initiative from the Institute for Human Development, Child and Youth Health, Grant number: NRFHPG-78880).

Tables

Table 1

General Characteristics of the Study Population

$\begin{array}{cccc}\text { Characteristics } & \text { LBW } & \text { NBW } & \text { Macrosomia } \\ (\boldsymbol{n}=175) & (\boldsymbol{n}=4935) & (\boldsymbol{n}=611)\end{array}$


Age, years, mean $\pm S D$

$29.69 \pm 4.55$

$29.52 \pm 4.30$

$29.86 \pm 4.02 \dagger$

BMI before pregnancy,

$23.79 \pm 5.68$

$24.16 \pm 5.14$

$26.36 \pm 6.05 \dagger$

$\mathrm{kg} / \mathrm{m}^{2}$, mean $\pm S D$

Ethnicity, $n(\%)$

2 Caucasian parents

$\begin{array}{cccccc}165 & (98.21) & 4570 & (97.01) & 560 & (96.72) \\ 3 & (1.79) & 141 & (2.99) & 19 & (3.28)\end{array}$

Not 2 Causasian parents

$3-(1.79)$

$(2.99)$

$19(3.28)$

Smoking status, $n(\%)$

Smoker

Ex-smoker

Never smoked

Alcohol consumption, $n(\%)$

0

$$
\leq 1 \text { per week }
$$

$>1$ per week

Drug consumption, $n(\%)$

Yes

No

Marital status, $n(\%)$

Married/Common law

Single

Highest education level,

$$
n(\%)
$$

No diploma

High school

Collegial

University

Annual family income,

\$CAN, $n(\%)$

$$
\begin{aligned}
& <40000 \\
& 40000-59999 \\
& \geq 60000
\end{aligned}
$$

Previous psychiatric

$\begin{array}{cccccc}46 & (26.29) \dagger & 616 & (12.49) & 43 & (7.06) \dagger \\ 33 & (18.86) & 1213 & (24.60) & 164 & (26.93) \\ 96 & (54.86) \dagger & 3101 & (62.90) & 402 & (66.01)\end{array}$

$\begin{array}{cccccc}145 & (91.19) & 4398 & (93.53) & 556 & (94.56) \\ 13 & (8.18) & 252 & (5.36) & 30 & (5.10) \\ 1 & (0.63) & 52 & (1.11) & 2 & (0.34) \dagger\end{array}$

$\begin{array}{cccccc}6 & (3.53) & 113 & (2.35) & 10 & (1.70) \\ 164 & (96.47) & 4690 & (97.65) & 579 & (98.30)\end{array}$

$\begin{array}{cccccc}159 & (91.38) & 4581 & (93.11) & 566 & (92.79) \\ 15 & (8.62) & 339 & (6.89) & 44 & (7.21)\end{array}$

$\begin{array}{llllll}12 & (6.90) & 187 & (3.80) & 22 & (3.61) \\ 52 & (29.89) & 1154 & (23.44) & 135 & (22.17) \\ 47 & (27.01) & 1606 & (32.62) & 199 & (32.68) \\ 63 & (36.21) & 1976 & (40.14) & 253 & (41.54)\end{array}$

$\begin{array}{llllll}46 & (28.57) & 996 & (21.75) & 107 & (18.90) \\ 32 & (19.88) & 1021 & (22.29) & 119 & (21.02) \\ 83 & (51.55) & 2563 & (55.96) & 340 & (60.07) \\ 23 & (14.74) \dagger & 377 & (7.93) & 38 & (6.33)\end{array}$


diagnosis, $n(\%)$

Note. LBW = low birth weight; NBW = normal birth weight; $\mathrm{BMI}=$ body mass index . $\dagger p<.05$ when compared to NBW

Table 2

Obstetrical Characteristics of the Study Population

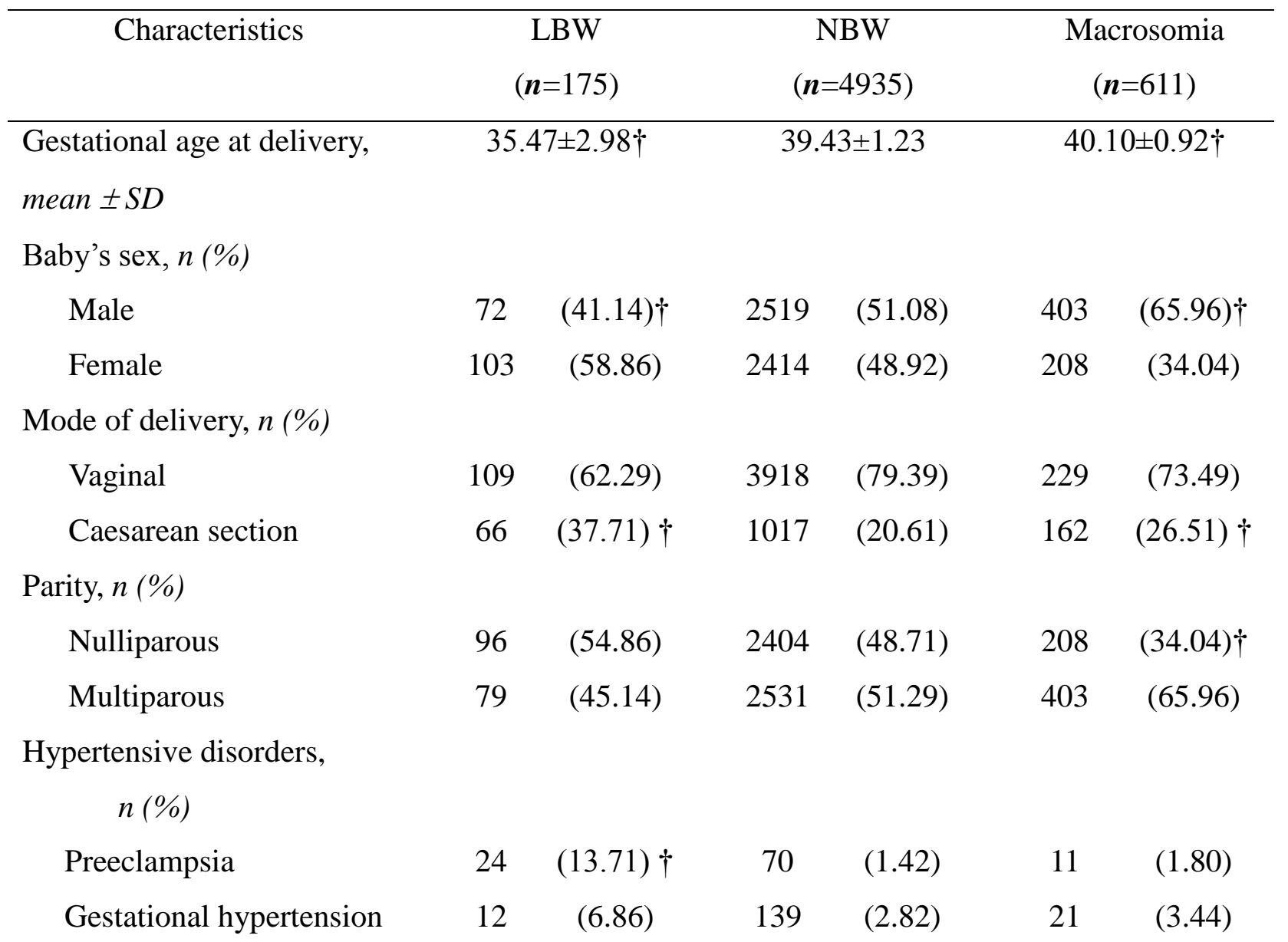

Glucose disorders, $n(\%)$ 


$\begin{array}{lcccccc}\text { GDM } & 13 & (7.43) & 219 & (4.44) & 38 & (6.22) \\ \quad \text { IGT } & 8 & (4.57) & 106 & (2.15) & 17 & (2.78) \\ \text { Previous preterm birth, } & 28 & (16.00) \dagger & 234 & (4.74) & 24 & (3.93) \\ \quad n(\%) & & & & & & \\ \quad \begin{array}{l}\text { Previous miscarriage, } n(\%) \\ \text { Previous pregnancy }\end{array} & 40 & (22.86) & 1087 & (22.03) & 136 & (22.26) \\ \text { termination, } n(\%) & 37 & (21.14) & 950 & (19.25) & 112 & (18.33) \\ & & & & & & \end{array}$

Note. $\mathrm{LBW}=$ low birth weight; $\mathrm{NBW}=$ normal birth weight; $\dagger=p<.05$ when compared to NBW.

Table 3

Association Between Psychological Stress and Birth weight

\begin{tabular}{|c|c|c|c|c|c|c|}
\hline \multirow[b]{2}{*}{$\begin{array}{l}\text { MSP-9 } \\
\text { score }\end{array}$} & \multicolumn{3}{|c|}{$\begin{array}{l}\text { LBW } \\
(n=175)\end{array}$} & \multicolumn{3}{|c|}{$\begin{array}{l}\text { Macrosomia } \\
\qquad(\mathrm{n}=611)\end{array}$} \\
\hline & $\begin{array}{c}\mathrm{n} \\
(\%)\end{array}$ & $\begin{array}{c}\text { Non-adjusted } \\
\text { OR } \\
\text { (CI 95\%) }\end{array}$ & $\begin{array}{l}\text { Adjusted OR* } \\
\qquad(\mathrm{CI} 95 \%)\end{array}$ & $\begin{array}{c}\mathrm{n} \\
(\%)\end{array}$ & $\begin{array}{c}\text { Non-adjusted } \\
\text { OR } \\
\text { (CI 95\%) }\end{array}$ & $\begin{array}{l}\text { Adjusted OR* } \\
\qquad(\mathrm{CI} 95 \%)\end{array}$ \\
\hline Low & $\begin{array}{c}65 \\
(37.14)\end{array}$ & 1 (Reference) & 1 (Reference) & $\begin{array}{c}229 \\
(37.48)\end{array}$ & 1 (Reference) & 1 (Reference) \\
\hline Intermediate & $\begin{array}{c}100 \\
(57.17)\end{array}$ & $\begin{array}{c}1.24(0.90-1.70) \\
p=.185\end{array}$ & $\begin{array}{c}1.37(0.88-2.12) \\
p=.116\end{array}$ & $\begin{array}{c}353 \\
(57.77)\end{array}$ & $\begin{array}{c}1.24(1.04-1.48) \\
p=.016\end{array}$ & $\begin{array}{c}1.23(1.02-1.49) \\
p=.027\end{array}$ \\
\hline High & $\begin{array}{c}10 \\
(5.71)\end{array}$ & $\begin{array}{c}2.06(1.04-4.09) \\
p=.038\end{array}$ & $\begin{array}{c}2.09(0.83-5.26) \\
p=.116\end{array}$ & $\begin{array}{c}29 \\
(4.74)\end{array}$ & $\begin{array}{c}1.70(1.12-2.58) \\
p=.013\end{array}$ & $\begin{array}{c}1.76(1.11-2.77) \\
p=.016\end{array}$ \\
\hline $\begin{array}{l}\text { weight gain } \\
\text { Boldface }=\mathrm{s} \\
\text { odds ratios. }\end{array}$ & $\begin{array}{l}\text { ing pre } \\
\text { iificant }\end{array}$ & $\begin{array}{l}\text { sestational age at } \\
\text { nancy, , smoking } \\
\text { esult. LBW = lov }\end{array}$ & $\begin{array}{l}\text { tus, sex of the } \\
\text { rth weight ; M }\end{array}$ & $\begin{array}{l}\text { y, hyl } \\
=\text { Mea }\end{array}$ & $\begin{array}{l}\text { nsive disorder } \\
\text { of Psycholog }\end{array}$ & $\begin{array}{l}\text { dy mass index, } \\
\text { uring pregnancy. } \\
\text { I Stress; OR = }\end{array}$ \\
\hline
\end{tabular}


Figure

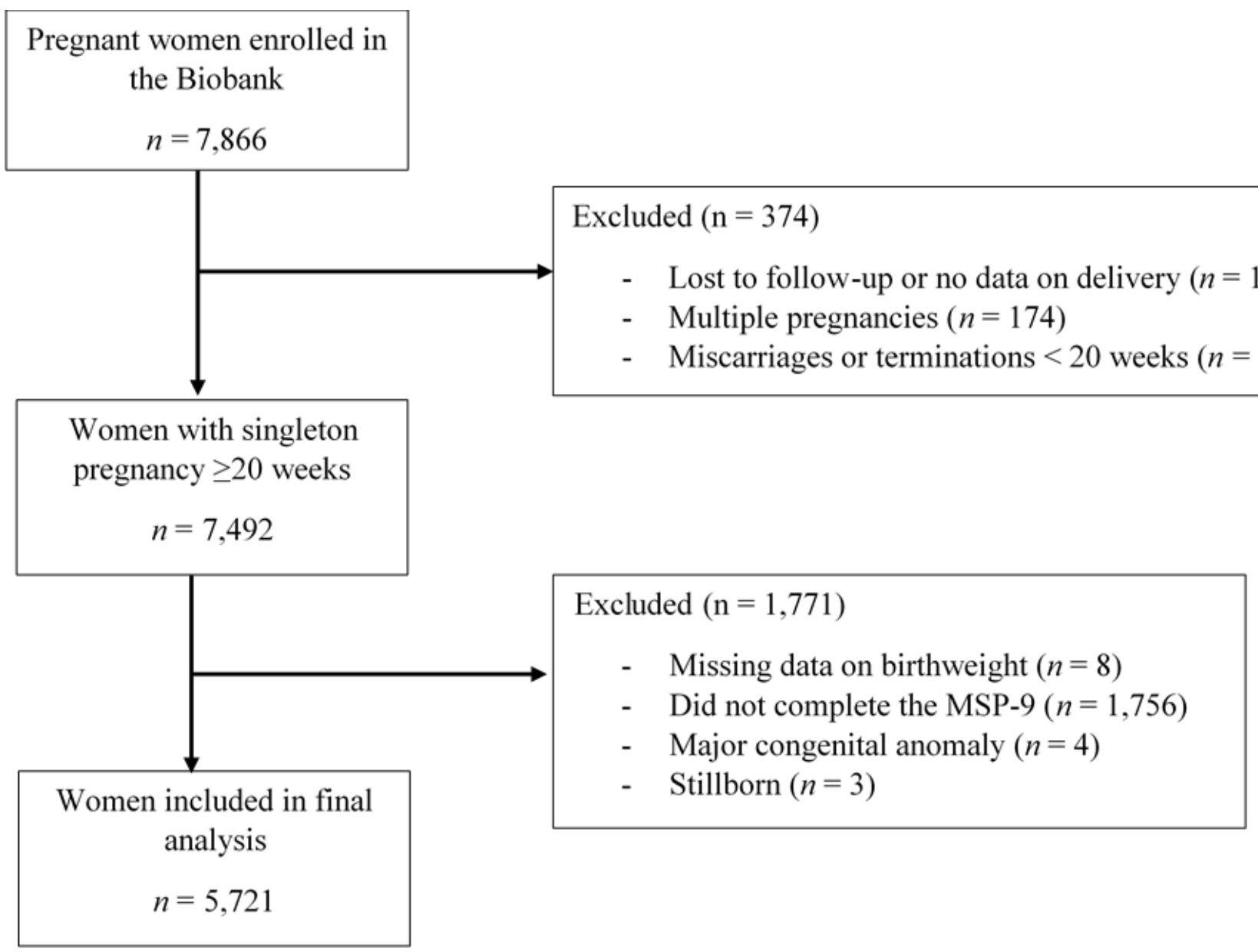

Figure 1. Flow chart of the sample selection for the study of the impact of the maternal psychological stress on birth. MSP = Measure of Psychological Stress.

\section{References}

Ay, L., Kruithof, C., Bakker, R., Steegers, E., Witteman, J., Moll, H., . . Jaddoe, V. (2009). Maternal anthropometrics are associated with fetal size in different periods of 
pregnancy and at birth. The Generation R Study. BJOG: An International Journal of Obstetrics \& Gynaecology, 116(7), 953-963.

Baschat, A. A., \& Hecher, K. (2004). Fetal growth restriction due to placental disease. Paper presented at the Seminars in perinatology.

Beaumont, R. N., Warrington, N. M., Cavadino, A., Tyrrell, J., Nodzenski, M., Horikoshi, M., . . . Freathy, R. M. (2018). Genome-wide association study of offspring birth weight in 86577 women identifies five novel loci and highlights maternal genetic effects that are independent of fetal genetics. Hum Mol Genet, 27(4), 742-756. doi:10.1093/hmg/ddx429

Beijers, R., Buitelaar, J. K., \& de Weerth, C. (2014). Mechanisms underlying the effects of prenatal psychosocial stress on child outcomes: beyond the HPA axis. Eur Child Adolesc Psychiatry, 23(10), 943-956. doi:10.1007/s00787-014-0566-3

Benedetti, T. J., \& Gabbe, S. G. (1978). Shoulder dystocia. A complication of fetal macrosomia and prolonged second stage of labor with midpelvic delivery. Obstetrics and Gynecology, 52(5), 526-529.

Bergman, I., Hirsch, R. P., Fria, T. J., Shapiro, S. M., Holzman, I., \& Painter, M. J. (1985). Cause of hearing loss in the high-risk premature infant. The Journal of pediatrics, 106(1), 95-101.

Bernard, N., Forest, J. C., Tarabulsy, G. M., Bujold, E., Bouvier, D., \& Giguere, Y. (2019). Use of antidepressants and anxiolytics in early pregnancy and the risk of preeclampsia and gestational hypertension: a prospective study. BMC Pregnancy Childbirth, 19(1), 146. doi:10.1186/s12884-019-2285-8

Borders, A. E., Grobman, W. A., Amsden, L. B., \& Holl, J. L. (2007). Chronic stress and low birth weight neonates in a low-income population of women. Obstet Gynecol, 109(2 Pt 1), 331-338. doi:10.1097/01.AOG.0000250535.97920.b5

Borders, A. E. B., Grobman, W. A., Amsden, L. B., \& Holl, J. L. (2007). Chronic stress and low birth weight neonates in a low-income population of women. Obstetrics \& Gynecology, 109(2), 331-338.

Boulet, S. L., Alexander, G. R., Salihu, H. M., \& Pass, M. (2003). Macrosomic births in the United States: determinants, outcomes, and proposed grades of risk. American journal of obstetrics and gynecology, 188(5), 1372-1378.

Boyd, M. E., Usher, R. H., \& Mclean, F. H. (1983). Fetal macrosomia: prediction, risks, proposed management. Obstetrics and Gynecology, 61(6), 715-722.

Bussieres, E.-L., Tarabulsy, G. M., Pearson, J., Tessier, R., Forest, J.-C., \& Giguere, Y. (2015). Maternal prenatal stress and infant birth weight and gestational age: A metaanalysis of prospective studies. Developmental Review, 36, 179-199.

Bussieres, E. L., Tarabulsy, G. M., Pearson, J., Tessier, R., Forest, J. C., \& Giguere, Y. (2015). Maternal prenatal stress and infant birth weight and gestational age: A metaanalysis of prospective studies. Developmental Review, 36, 179-199.

Cai, Q. Y., Zhang, H. X., Wang, C. C., Sun, H., Sun, S. Q., Wang, Y. H., . . Yang, X. J. (2017). Placental and cord blood brain derived neurotrophic factor levels are decreased in nondiabetic macrosomia. Arch Gynecol Obstet, 296(2), 205-213. doi:10.1007/s00404-017-4414-9

Canadian Institute for Health Information. (2009). Too Early, Too Small: A Profile of Small Babies Across Canada: CIHI Ottawa, ON.

de Bernabé, J. V., Soriano, T., Albaladejo, R., Juarranz, M., Calle, M. a. E., Martínez, D., \& Domínguez-Rojas, V. (2004). Risk factors for low birth weight: a review. European Journal of Obstetrics \& Gynecology and Reproductive Biology, 116(1), 3-15. 
Dolatian, M., Mahmoodi, Z., Alavi-Majd, H., Moafi, F., Ghorbani, M., \& Mirabzadeh, A. (2016). Psychosocial factors in pregnancy and birthweight: Path analysis. Journal of Obstetrics and Gynaecology Research, 42(7), 822-830.

Dubois, L., Girard, M., \& Tatone-Tokuda, F. (2007). Determinants of high birth weight by geographic region in Canada. Chronic Dis Can, 28(1-2), 63-70.

Dunn, H., Robertson, A.-M., \& Crichton, J. (1986). Clinical outcome: neurological sequelae and their evolution. Clinics in developmental medicine(95-96), 68-96.

Ellenberg, J. H., \& Nelson, K. B. (1979). Birth weight and gestational age in children with cerebral palsy or seizure disorders. American journal of diseases of children, 133(10), 1044-1048.

Field, T., Hernandez-Reif, M., Diego, M., Figueiredo, B., Schanberg, S., \& Kuhn, C. (2006). Prenatal cortisol, prematurity and low birthweight. Infant Behav Dev, 29(2), 268-275. doi:10.1016/j.infbeh.2005.12.010

Fowden, A., Forhead, A., Coan, P., \& Burton, G. (2008). The placenta and intrauterine programming. Journal of neuroendocrinology, 20(4), 439-450.

Gallo, J. E., \& Lennerstrand, G. (1991). A population-based study of ocular abnormalities in premature children aged 5 to 10 years. American journal of ophthalmology, 111(5), 539-547.

Gennaro, S., \& Hennessy, M. D. (2003). Psychological and physiological stress: impact on preterm birth. J Obstet Gynecol Neonatal Nurs, 32(5), 668-675.

Giguere, Y., Masse, J., Theriault, S., Bujold, E., Lafond, J., Rousseau, F., \& Forest, J. C. (2015). Screening for pre-eclampsia early in pregnancy: performance of a multivariable model combining clinical characteristics and biochemical markers. BJOG, 122(3), 402-410. doi:10.1111/1471-0528.13050

Gilles, M., Otto, H., Wolf, I. A. C., Scharnholz, B., Peus, V., Schredl, M., . . Deuschle, M. (2018). Maternal hypothalamus-pituitary-adrenal (HPA) system activity and stress during pregnancy: Effects on gestational age and infant's anthropometric measures at birth. Psychoneuroendocrinology, 94, 152-161. doi:10.1016/j.psyneuen.2018.04.022

Hashim, T. J., \& Moawed, S. A. (2000). The relation of low birth weight to psychosocial stress and maternal anthropometric measurements. Saudi medical journal, 21(7), 649654.

Hobel, C., \& Culhane, J. (2003). Role of psychosocial and nutritional stress on poor pregnancy outcome. The Journal of nutrition, 133(5), 1709S-1717S.

Jakubauskiene, L., Jakubauskas, M., Mainelis, A., Buzinskiene, D., Drasutiene, G., Ramasauskaite, D., \& Poskus, T. (2019). Factors Influencing Quality of Life during the First Trimester of Pregnancy: A Prospective Cohort Study. Medicina (Kaunas), 55(10). doi:10.3390/medicina55100666

John, R. M. (2017). Imprinted genes and the regulation of placental endocrine function: Pregnancy and beyond. Placenta, 56, 86-90. doi:10.1016/j.placenta.2017.01.099

Jolly, M. C., Sebire, N. J., Harris, J. P., Regan, L., \& Robinson, S. (2003). Risk factors for macrosomia and its clinical consequences: a study of 350,311 pregnancies. European Journal of Obstetrics \& Gynecology and Reproductive Biology, 111(1), 9-14.

Khashan, A., Everard, C., McCowan, L., Dekker, G., Moss-Morris, R., Baker, P., . . Kenny, L. (2014). Second-trimester maternal distress increases the risk of small for gestational age. Psychological medicine, 44(13), 2799-2810.

Kraybill, E. N., Bose, C. L., \& D'ercole, A. J. (1987). Chronic lung disease in infants with very low birth weight: a population-based study. American Journal of Diseases of Children, 141(7), 784-788.

Langevin, V., François, M., Boini, S., \& Riou, A. (2012). La mesure du stress psychologique (MSP). Documents pour le Médecin du Travail(129). 
Lemyre, L., \& Tessier, R. (2003). Hypothèse: la Page de la recherche: La mesure stress stress psychologique en recherche de première ligne: Concept, modèle et mesure. Canadian family physician, 49, 1166-1168.

Liou, S.-R., Wang, P., \& Cheng, C.-Y. (2016). Effects of prenatal maternal mental distress on birth outcomes. Women and Birth, 29(4), 376-380.

Lobel, M., Cannella, D. L., Graham, J. E., DeVincent, C., Schneider, J., \& Meyer, B. A. (2008). Pregnancy-specific stress, prenatal health behaviors, and birth outcomes. Health Psychology, 27(5), 604.

McCormick, M. C., Gortmaker, S. L., \& Sobol, A. M. (1990). Very low birth weight children: behavior problems and school difficulty in a national sample. The Journal of pediatrics, 117(5), 687-693.

Mohammadbeigi, A., Farhadifar, F., Soufizadeh, N., Mohammadsalehi, N., Rezaiee, M., \& Aghaei, M. (2013). Fetal macrosomia: risk factors, maternal, and perinatal outcome. Annals of medical and health sciences research, 3(3), 546-550.

Nelissen, E. C., van Montfoort, A. P., Dumoulin, J. C., \& Evers, J. L. (2011). Epigenetics and the placenta. Hum Reprod Update, 17(3), 397-417. doi:10.1093/humupd/dmq052

Nkansah-Amankra, S., Luchok, K. J., Hussey, J. R., Watkins, K., \& Liu, X. (2010). Effects of maternal stress on low birth weight and preterm birth outcomes across neighborhoods of South Carolina, 2000-2003. Maternal and child health journal, 14(2), 215-226.

Rakers, F., Rupprecht, S., Dreiling, M., Bergmeier, C., Witte, O. W., \& Schwab, M. (2017). Transfer of maternal psychosocial stress to the fetus. Neuroscience \& Biobehavioral Reviews.

Resch, Z. T., Oxvig, C., Bale, L. K., \& Conover, C. A. (2006). Stress-activated signaling pathways mediate the stimulation of pregnancy-associated plasma protein-A expression in cultured human fibroblasts. Endocrinology, 147(2), 885-890. doi:10.1210/en.2005-0908

Roberts, C. T., White, C. A., Wiemer, N. G., Ramsay, A., \& Robertson, S. A. (2003). Altered placental development in interleukin-10 null mutant mice. Placenta, 24 Suppl A, S9499. doi:10.1053/plac.2002.0949

Rondó, P. H., Ferreira, R. F., Nogueira, F., Ribeiro, M., Lobert, H., \& Artes, R. (2003). Maternal psychological stress and distress as predictors of low birth weight, prematurity and intrauterine growth retardation. European journal of clinical nutrition, 57(2), 266.

Roy-Matton, N., Moutquin, J.-M., Brown, C., Carrier, N., \& Bell, L. (2011). The impact of perceived maternal stress and other psychosocial risk factors on pregnancy complications. Journal of Obstetrics and Gynaecology Canada, 33(4), 344-352.

Sonmez, E. O., Uguz, F., Sahingoz, M., Sonmez, G., Kaya, N., Camkurt, M. A., . . . Tasyurek, E. (2019). Effect of Maternal Depression on Brain-derived Neurotrophic Factor Levels in Fetal Cord Blood. Clin Psychopharmacol Neurosci, 17(2), 308-313. doi:10.9758/cpn.2019.17.2.308

Statistics Canada. (2016). Table 13-10-0745-01 Birth-related indicators (low and high birth weight, small and large for getational age, preterm births), by sex, three-year period, health regions and peer groups. Retrieved from https://doi.org/10.25318/1310074501-eng

Stylianou-Riga, P., Kouis, P., Kinni, P., Rigas, A., Papadouri, T., Yiallouros, P. K., \& Theodorou, M. (2018). Maternal socioeconomic factors and the risk of premature birth and low birth weight in Cyprus: a case-control study. Reprod Health, 15(1), 157. doi:10.1186/s12978-018-0603-7

Tarabulsy, G. M., Pearson, J., Vaillancourt-Morel, M.-P., Bussières, E.-L., Madigan, S., Lemelin, J.-P., . . Royer, F. (2014). Meta-analytic findings of the relation between 
maternal prenatal stress and anxiety and child cognitive outcome. Journal of Developmental \& Behavioral Pediatrics, 35(1), 38-43.

Tegethoff, M., Greene, N., Olsen, J., Meyer, A. H., \& Meinlschmidt, G. (2010a). Maternal psychosocial adversity during pregnancy is associated with length of gestation and offspring size at birth: evidence from a population-based cohort study. Psychosomatic medicine, 72(4), 419-426.

Tegethoff, M., Greene, N., Olsen, J., Meyer, A. H., \& Meinlschmidt, G. (2010b). Maternal psychosocial stress during pregnancy and placenta weight: evidence from a national cohort study. PloS one, 5(12), e14478.

Theriault, S., Giguere, Y., Masse, J., Girouard, J., \& Forest, J. C. (2016). Early prediction of gestational diabetes: a practical model combining clinical and biochemical markers. Clin Chem Lab Med, 54(3), 509-518. doi:10.1515/cclm-2015-0537

Togher, K. L., O'Keeffe, G. W., Khashan, A. S., Clarke, G., \& Kenny, L. C. (2018). Placental FKBP51 mediates a link between second trimester maternal anxiety and birthweight in female infants. Sci Rep, 8(1), 15151. doi:10.1038/s41598-018-33357-3

Uguz, F., Sonmez, E. O., Sahingoz, M., Gokmen, Z., Basaran, M., Gezginc, K., . . Tasyurek, E. (2013). Maternal generalized anxiety disorder during pregnancy and fetal brain development: a comparative study on cord blood brain-derived neurotrophic factor levels. J Psychosom Res, 75(4), 346-350. doi:10.1016/j.jpsychores.2013.04.010

United Nations Children's Fund and World Health Organization. (2004). Low Birthwight: country, regional and global estimates. New York.

Wadhwa, P. D., Sandman, C. A., Porto, M., Dunkel-Schetter, C., \& Garite, T. J. (1993). The association between prenatal stress and infant birth weight and gestational age at birth: a prospective investigation. American journal of obstetrics and gynecology, 169(4), 858-865.

Wang, D., Zhu, L., Zhang, S., Wu, X., Wang, X., Lv, Q., . . Zhou, Q. (2016). Predictive macrosomia birthweight thresholds for adverse maternal and neonatal outcomes. The Journal of Maternal-Fetal \& Neonatal Medicine, 29(23), 3745-3750.

Woolcott, C. G., Giguere, Y., Weiler, H. A., Spencer, A., Forest, J. C., Armson, B. A., \& Dodds, L. (2016). Determinants of vitamin D status in pregnant women and neonates. Can J Public Health, 107(4-5), e410-e416. doi:10.17269/cjph.107.5629

Ye, J., Torloni, M. R., Ota, E., Jayaratne, K., Pileggi-Castro, C., Ortiz-Panozo, E., . . Mori, R. (2015). Searching for the definition of macrosomia through an outcome-based approach in low-and middle-income countries: a secondary analysis of the WHO Global Survey in Africa, Asia and Latin America. BMC pregnancy and childbirth, 15(1), 324. 